\title{
Finite element simulation of seismically induced retrogressive failure of submarine slopes
}

\author{
A. Azizian and R. Popescu
}

\begin{abstract}
Retrogressive failures have been reported for both offshore and onshore slopes subjected to various triggering mechanisms. As a result of large spatial extension of the failure, the retrogression phenomenon leads to significantly increasing damage and may affect facilities located far away from the original slope. The mechanisms of such failures are not fully understood, and reports of analyses are rather scarce. To simulate earthquake-induced retrogressive submarine slope failures and to better understand the mechanisms involved, the element removal capabilities of a finite element program are used to model a soil mass that fails and then flows away, causing upper parts of the slope to fail retrogressively, as a result of the loss of support. It is explained how an initial failure leads to subsequent failures of a flat seafloor. Effects of a shallow silt layer and of a gently sloping seafloor on the extension of retrogression in a sandy seabed are also studied. It is found that the extension of failure increases significantly because of a gentle seafloor slope and (or) the presence of a silt layer.
\end{abstract}

Key words: retrogressive submarine failure, seismic liquefaction, finite elements.

Résumé : On a rapporté des ruptures en rétrogression sur des pentes de fond de mer ou sur la rive assujetties à divers mécanismes de déclenchement. À cause de la grande extension spatiale de la rupture, le phénomène de rétrogression mène à un accroissement appréciable des dommages et peut affecter des installations situées loin de la pente originale. Les mécanismes de telles ruptures ne sont pas très bien compris, et les rapports d'analyse sont plutôt rares. Pour simuler les ruptures en rétrogression des pentes sous-marines induites par une secousse sismique, et pour mieux comprendre les mécanismes impliqués, on utilise le potentiel de suppression d'éléments dans un programme d'éléments finis pour modéliser un massif de sol qui atteint la rupture et s'écoule, causant une rupture des parties supérieures de la pente par rétrogression causée par la perte de soutien. On explique comment une rupture initiale conduit à des ruptures subséquentes d'un fond de mer plat. On étudie également les effets d'une mince couche de silt et d'un fond de mer légèrement pentu sur l'extension de la rétrogression dans un fond de mer sableux. On trouve que l'extension de la rupture s'accroît de façon significative à cause d'une pente légère de fond de mer et/ou de la présence d'une couche de silt.

Mots clés : rupture sous-marine en rétrogression, liquéfaction séismique, éléments finis.

[Traduit par la Rédaction]

\section{Introduction}

One of the key features of submarine landslides, especially those involving very huge scars and considerable travel distances for debris or mudflows, is a retrogressive pattern (Mulder and Cochonat 1996). Retrogressive failures have had different impacts on offshore and coastal facilities. Such a mechanism can contribute to some unique characteristics of submarine slides, such as huge volumes of mass movement, very long displacement of slide blocks, and development of the slide on nearly flat surfaces and (or) in layered deposits (Hampton et al. 1996).

A first objective of this study is to introduce a method for simulating seismically induced retrogressive slope failures by using nonlinear, dynamic finite element analysis (FEA) and to explain the basic mechanisms of such phenomena, in- cluding the initial slope failure during or immediately after the earthquake and subsequent failures of a flat seafloor. A second objective is to use the method to investigate the effects of a silt layer and of a gently sloping seafloor on the extension of retrogression in a sand deposit.

The analyses reported in this paper address only the seismic triggering mechanism of retrogressive failures. The importance of accounting for the retrogression effect is illustrated for four cases with different soil profiles and seafloor slope conditions. The effects of mesh size are also investigated for one of those cases. It is shown that for the type of FEA performed in this study, the extent of failure when the phenomenon of retrogression is simulated by removal of failed soil material is much greater than when no removal is performed. Such an analysis can provide a better estimate of the stability of a region, since neglecting the pos-

A. Azizian ${ }^{1}$ and R. Popescu. Faculty of Engineering and Applied Science, Memorial University of Newfoundland, St. John's, NL A1B 3X5, Canada.

${ }^{1}$ Corresponding author (e-mail: azizian@engr.mun.ca). 
Fig. 1. Classification of successive submarine slumps or slides (after Mulder and Cochonat 1996).

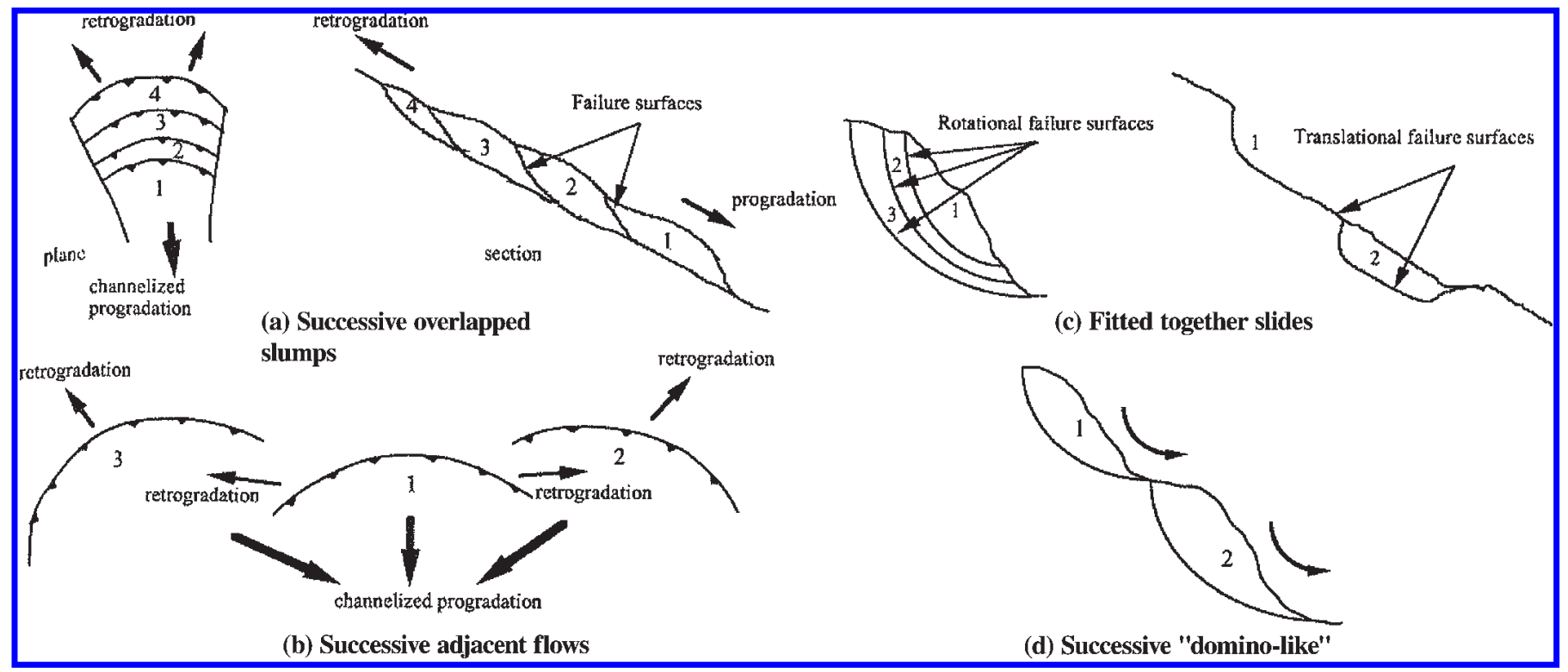

sibility of retrogression phenomenon may result in nonconservative predictions.

\section{Submarine retrogressive failures}

According to Hampton et al. (1996), sliding that occurs serially as numerous adjacent failures that progress upslope is termed retrogressive. Some unique characteristics of submarine slides, such as huge volumes of mass movement, vast scars, very long displacement of slide blocks, considerable travel distances for debris or mudflows, and development of the slide on nearly flat surfaces, are believed to be caused, at least in part, by retrogression effects (Edwards et al. 1995; Hampton et al. 1996; Mulder and Cochonat 1996).

Retrogressive slides have occurred in both offshore (continental margin and deep ocean) and nearshore environments. Some recent slides originated near shore and retrogressed across the shoreline. Examples of such failures are the catastrophic slides in Seward and Valdez during the 1964 Alaska earthquake (Lemke 1967) and the 1888 Trondheim Harbour slide, Norway (Andersen and Bjerrum 1967). On land, such failures have been reported and documented in many areas, especially in Scandinavia and eastern Canada in extrasensitive quick clays (Terzaghi et al. 1996).

Flow failures in submarine loose sand, silt, and sensitive clays are often retrogressive. Some adjacent flow failures are very common in loose sandy and silty deposits in the Finnish and Norwegian fjords (Terzaghi 1956; Andersen and Bjerrum 1967), as well as on the Atlantic and Pacific margins of Canada and the United States (Hampton et al. 1996; Piper et al. 1999). Some of these failures seem linked to low tides, where the excess pore pressure generated during high tide does not have enough time to dissipate during the ebb (Andersen and Bjerrum 1967). Rapid sedimentation is a triggering mechanism in the Mississippi River delta, which has resulted in numerous retrogressive slides (Prior and Coleman 1978). In addition, other environmental processes, such as the formation of gas hydrates, can contribute to the initiation and acceleration of retrogression (e.g., Hampton et al. 1996).
Notable examples of earthquake-induced instabilities are the following (see also Chillarige et al. 1997; Seed 1968): the Grand Banks slide (1929), Newfoundland, Canada (Piper et al. 1999); Vancouver Island slides (1946), British Columbia, Canada (Mosher et al. 2001); the Valdez slide (1964), Alaska, United States (Lemke 1967); the Saguenay Fjord slide, Quebec, Canada (Urgeles et al. 2001); the Storegga slide, Norway (e.g., Bugge et al. 1987); the Karmsundet and Skudenesfjorden slides, Norway (Boe et al. 2000); and the Humboldt slide, northern California, United States (Gardner et al. 1999).

On the basis of observations on numerous landslides worldwide, Mulder and Cochonat (1996) classified retrogressive failures as follows (Fig. 1):

(i) Successive overlapped: The failure surface of the main body (i.e., initial failure) is merged with the failure surfaces of the following failures.

(ii) Adjacent: The main body triggers instability along the whole perimeter of the scar; this type of failure is not so frequent.

(iii) Fitted together (or additive): The failure surface of the main body is not merged with the failure surfaces of the following failures.

(iv) Domino-like: A topographically high mass of sediment fails and induces mobility in an underlying second material mass; this type is infrequent.

In this study, retrogressive failures of the first type, that is, successive overlapped, are simulated.

Surficial ridges, inclined, truncated seismic reflections, rotated blocks, basal and internal shear surfaces, and distal sediment compression are some of the typical characteristics and visual features of submarine retrogressive slides appearing in seafloor images and seismic reflection profiles (e.g., Piper et al. 1992; Gardner et al. 1999; Boe et al. 2000; Locat and Lee 2002).

Limitation (i.e., stop of retrogression) mechanisms proposed in different sources (e.g., Andersen and Bjerrum 1967; Piper et al. 1999; Chillarige et al. 1997; Carson and Lajoie 
1981; Prior and Coleman 1984; Anderson and Richards 1987) include the following:

(i) topographic constraints, such as volume of the receiving valley or channel, shape of the scar, upslope gradient change, stable back scarp angle, and other stratigraphic changes; and

(ii) geomechanical factors, such as the existence of dense sands with dilative post-yield behaviour, overconsolidated, nonsensitive clays, and more permeable soils that allow rapid drainage.

From a geotechnical point of view, some researchers have explained the mechanism of retrogressive failures. For example, Haug et al. (1976) used the limit equilibrium method (factor of safety approach) to study a failure near the Saskatchewan River; Sladen et al. (1985) proposed the concept of a collapse surface concept for the Nerlerk Berm submarine failure; Mitchell and Markell (1974) and Leroueil et al. (1996), among others, used classical undrained slope stability analysis and the stability number for clays in their studies; and Chillarige et al. (1997) applied a state boundary surface concept to Fraser River delta submarine failures of sand deposits. Chillarige et al. (1997) attributed the retrogressive flow slides of the Fraser River delta sediments to the undrained stress redistribution after pore pressure changes due to low tides. After low tides that result in some initial flow failures, sediments that have already experienced some partially drained residual pore pressures can undergo stress redistribution, which can be sufficient to bring the state of the sediments onto the "contractant state boundary surface", a surface in $p^{\prime}-q-e$ space that controls the behaviour of purely contractant sands at large strains and envelopes all the undrained effective stress paths of such soils (Sasitharan et al. 1993). The redistribution can cause strain softening of the remaining unsupported sediments, which results in another flow slide and hence retrogression of failure. Such slides cease to progress when a denser soil deposit or a stable back scarp is encountered.

An alternative approach to the analysis of retrogressive failures, especially for estimating the debris runout distance, implements the tools and concepts of computational fluid dynamics. Kvalstad et al. (2002) used FEA and a computational fluid dynamics program (CFX-4 code, AEA Technology, 1999), for a headwall scarp left by the Storegga slide (off Norway, occurred ca. 8000 years ago). involving clay deposits. In this study, the effects of sensitivity and brittleness on the development of progressive failure are evaluated. A nonlinear strain softening material model is applied for the stability analysis of the slope material. The runout distance analysis is carried out with the CFX-4 program, modelling soil as a Bingham fluid with intact and residual yield strength and a strength degradation model controlling the reduction in strength as a function of strain.

According to Kvalstad et al. (2002), reduction in strength below the failure limit and softening toward remoulded strength "leads to run out and separation of out-runner block". The simulation of runout carried out by the CFX-4 program indicates that the material travels up to several hundred metres.

De Blasio et al. (2003) and Issler et al. (2003) also performed numerical simulations of the debris flow that occurred in the large Storegga slide (phase 1) and at a partic- ular location of the slide (Ormen Lange), respectively. In these studies, a Bingham (viscoplastic) model is used for the clay material to assess the effects of such parameters as the shear resistance between the debris flow and the seabed on runout distance. Since the numerical simulation results in runout distances much smaller than the observed typical runout distance in the Ormen Lange area (15-20 km), Issler et al. (2003) explained how some processes, such as remoulding, wetting, and hydroplaning, can reduce the shear resistance and thus lead to re-producing of a profile that is in agreement with the observed post-failure profile of debris deposition.

Certainly, ignoring the possibility of a retrogression mechanism will result in neglecting a considerable risk of damage to coastal or offshore infrastructure. In a complete landslide hazard analysis, the susceptibility classes should include gently sloping or even flat seabed above and below unstable slopes, where the hazard may be increased owing to retrogressive failures and debris runout, respectively (Hansen 1984). Such analysis requires detailed morphological mapping of a given area, including seismic surveys, to locate the signature of submarine failures and their types.

\section{Finite element simulation}

\section{Numerical model}

\section{Finite element code}

A multiyield plasticity soil constitutive model implemented in the finite element program, DYNAFLOW (Prévost 2002), was used in this study. DYNAFLOW is a state-of-the-art general-purpose FEA program for linear and nonlinear, twoand three-dimensional systems. Coupled analysis of porous media was performed to simulate the behaviour of saturated soil materials under partially drained conditions, by means of an extension of Biot's formulation in the nonlinear regime.

The multiyield plasticity model is a kinematic hardening model based on a relatively simple plasticity theory (Prévost 1985) and is applicable to both cohesive and cohesionless soils. The concept of a "field of work-hardening moduli" is used by defining a collection of nested yield surfaces in the stress space. Rounded Mohr-Coulomb yield surfaces were employed in this study. The yield surfaces define regions of constant shear moduli in the stress space, and in this manner the model discretizes the smooth elastic-plastic stress-strain curve into a number of linear segments. The outermost surface, that is, the failure surface, corresponds to zero shear modulus. The plastic flow rule is associative in its deviatoric component. A non-associative flow rule is used for the dilational component, to reflect the dependency of plastic dilatancy on the effective stress ratio. The material hysteretic behaviour and shear-stress-induced anisotropic effects are simulated by a purely kinematic hardening rule. Altogether, accurate simulation of shear-induced plastic dilation, hysteretic effects, and full solid-fluid coupling leads to a more precise calculation of excess pore-water pressure (EPWP) buildup-dissipation, as well as gradual soil softeninghardening during and after the earthquake shaking.

The required constitutive model parameters can be derived from the results of conventional laboratory and (or) in situ 
Fig. 2. General form of the finite element meshes used in this study: $(a)$ standard; and $(b)$ fine.
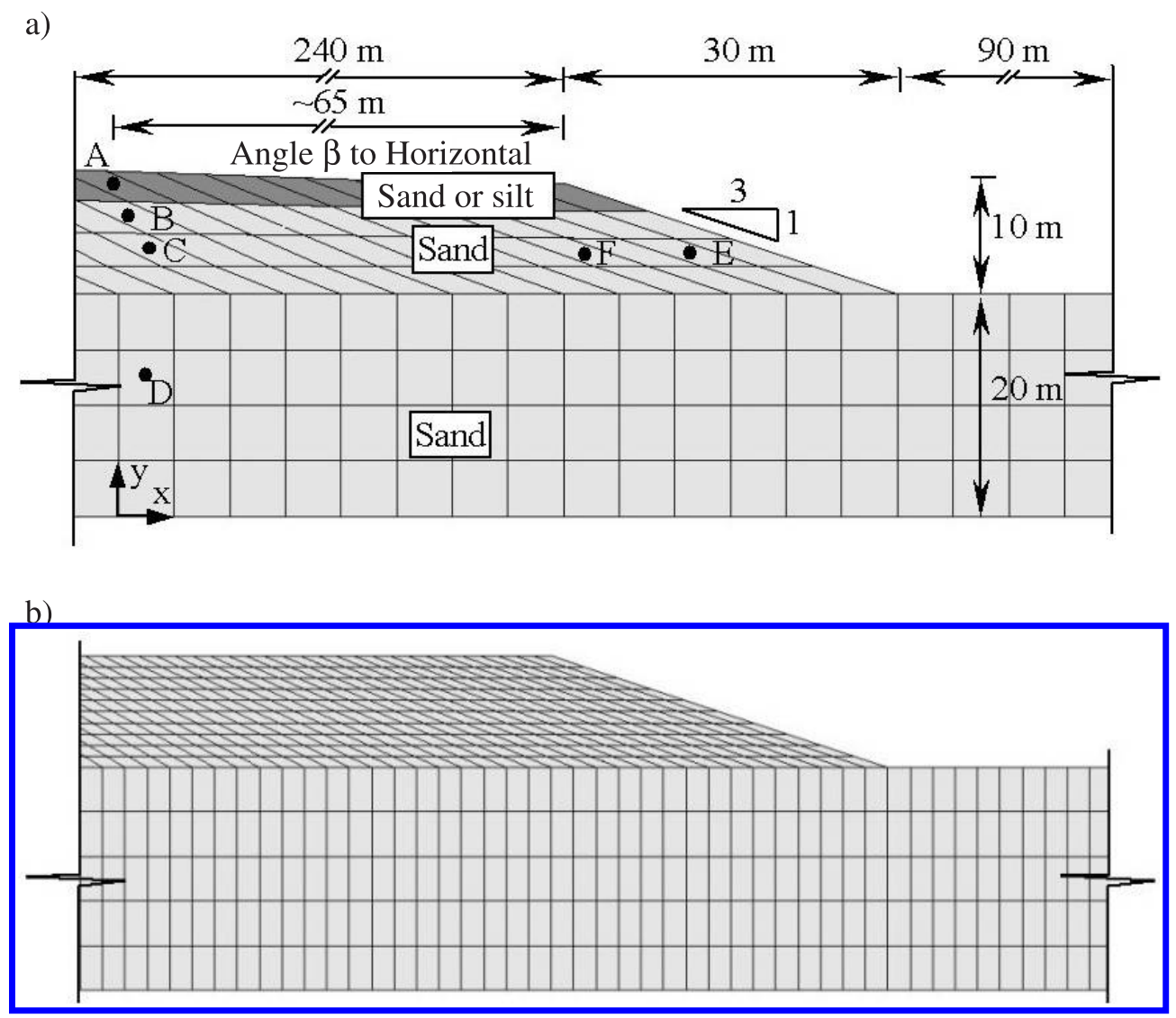

soil tests and liquefaction strength analysis (see, e.g., Popescu and Prévost 1993; Popescu 1995). The soil constitutive model, its implementation algorithm, and the methodology for estimating the constitutive model parameters have been repeatedly validated in the past for soil liquefaction computations based on both full-scale measurements and centrifuge experimental results (e.g., Keane and Prévost 1989; Popescu and Prévost 1993, 1995; Popescu et al. 1992, 1998).

\section{Finite element mesh}

In this study, two-dimensional, plane-strain FEAs were performed using the typical finite element mesh, as shown in Fig. $2 a$, in which the 1:3 vertical/horizontal $(V / H)$ front slope is followed by a flat or nearly flat seafloor. In this article, the term "slope" will be used for the 1:3 front slope, and "seafloor" will be used for the flat (or nearly flat) area situated to the left of the slope. In all the cases reported here, the seafloor is either flat $\left(\beta=0^{\circ}\right)$ or gently sloping $\left(\beta=2^{\circ}\right)$, and the slope is the same (at an angle of about $18^{\circ}$ ) in all cases. The lateral boundaries are located 240 and $90 \mathrm{~m}$ to the left and right of the slope crest and toe, respectively.

The selection of the slope angle $(1: 3 \mathrm{~V} / \mathrm{H})$ was based on the geometry of the slope to be analysed by centrifuge experiments as part of the Continental Slope Stability (COSTA)-Canada project (see COSTA-Canada 2000). In this study, the purpose was to predict the extension of failure beyond the limits of the centrifuge box. Nonetheless, the geometry also resembled to some extent some field situations, for example, a scarp left by the gigantic Storegga slide (see, e.g., Kvalstad et al. 2002).

For study of the effect of mesh size, a finer mesh (Fig. 2b) was used; it was about 2.5 times finer (by length) than the mesh in Fig. 2a. These two meshes will be referred to here as standard and fine mesh.

The soil was discretized into bilinear, quadrilateral finite elements, with four degrees of freedom per node, corresponding to the vertical and horizontal components of solid and fluid displacements. The standard and the fine meshes had 544 and 1275 elements, respectively.

\section{Material properties}

As shown in Fig. 2, two types of soil were used in this study: liquefiable sand, and silt. The soil properties, given in Table 1, were mainly based on the values calibrated from the results of Verification of Liquefaction Analysis by Centrifuge Studies (VELACS) project laboratory soil tests for Nevada sand, at a relative density of $D_{\mathrm{r}}=40 \%$, and Bonnie silt. The soil constitutive model parameters are listed in Table 1, and the procedure for estimating the soil properties was described by Popescu and Prévost (1993). A purely contractive behaviour was considered for both soils: that is, the values of friction angle at failure and the phase transformation angle are assumed equal.

\section{Boundary conditions and earthquake loading}

The earthquake motion is applied at the base and at the two lateral boundaries of the analysis domain, which are assumed rigid and are placed away from the slope. Specifically, 
Table 1. Soil properties.

\begin{tabular}{lll}
\hline Soil property & Sand & Silt \\
\hline Mass density-solid $\left(\mathrm{kg} / \mathrm{m}^{3}\right)$ & 2670.0 & 2670.0 \\
Porosity & 0.424 & 0.440 \\
Low-strain shear modulus $(\mathrm{MPa})$ & 25.0 & 7.5 \\
Low-strain bulk modulus $(\mathrm{MPa})$ & 54.2 & 35.0 \\
Reference mean effective normal stress $(\mathrm{kPa})$ & 40.0 \\
Power exponent & 100.0 & 1.0 \\
Fluid bulk modulus $(\mathrm{MPa})$ & 0.7 & 2000.0 \\
Friction angle at failure & 2000.0 & 28.0 \\
Cohesion $(\mathrm{kPa})$ & 31.0 & 0.0 \\
Maximum deviatoric strain in compression and in extension $(\%)$ & 0.0 & $8.0,8.0$ \\
Dilation angle & $8.0,7.0$ & 28.0 \\
Dilation parameter, $X_{\mathrm{pp}}$ & 31.0 & 0.04 \\
Coefficient of earth pressure at rest & 0.10 & 0.6 \\
Permeability $(\mathrm{m} / \mathrm{s})$ & 0.6 & $1.0 \times 10^{-8}$ \\
\hline
\end{tabular}

Fig. 3. Acceleration time history with $0.3 g$ peak ground acceleration.

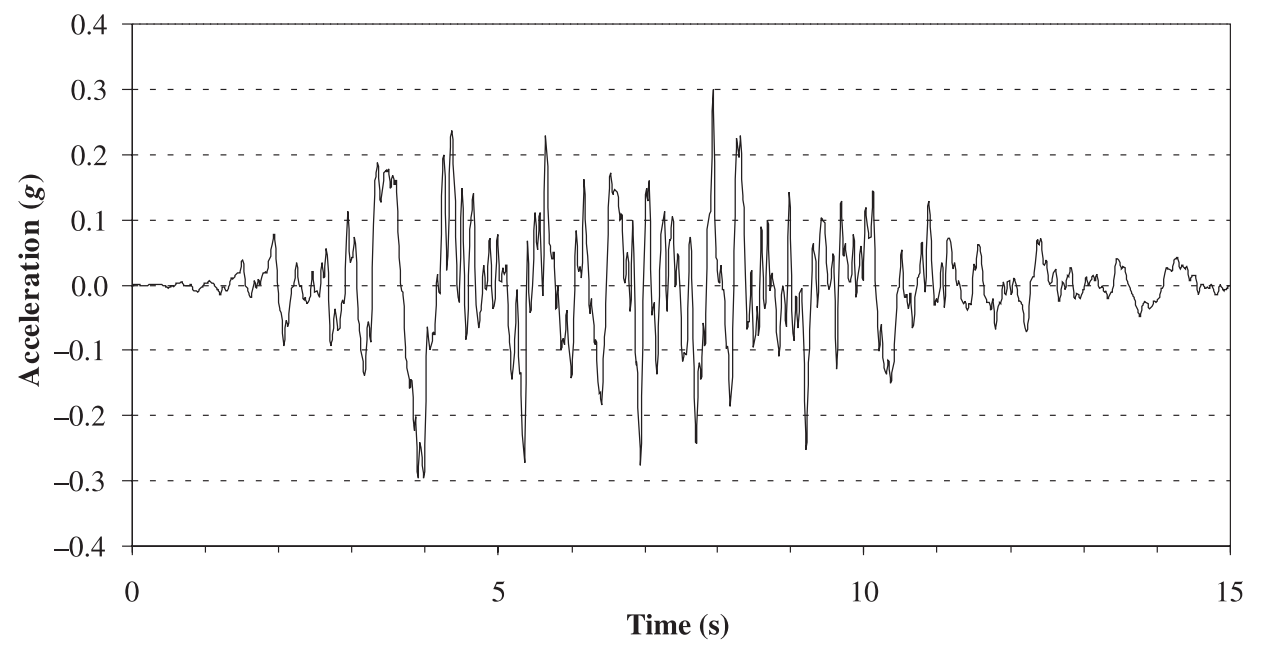

boundary conditions at the base simulate the presence of rigid, impervious bedrock, as follows: $(i)$ for the solid phase, prescribed horizontal acceleration and fixed displacement in the vertical direction; and (ii) for the fluid phase, free displacement in the horizontal direction and fixed displacement in the vertical direction. The boundary conditions at the lateral boundaries of the mesh are prescribed horizontal acceleration and free vertical displacement for both solid and fluid phases. The earthquake motion is an acceleration-time history generated from the response spectrum for soil type 3 (soft to medium clays and sands) recommended by the Uniform Building Code (ICBO 1994). The peak ground acceleration is scaled to $0.30 \mathrm{~g}$, and the duration of the strong motion is approximately $15 \mathrm{~s}$ (Fig. 3). The analysis time is extended to 300-400 s to capture the end of retrogression.

\section{Analysis procedure}

The main idea of the procedure is to remove one or more groups of elements at certain instants, to simulate volumes of soil that fail and flow away, for example, as parts of a debris flow. The analysis procedure is therefore iterative, because the decision on element removal cannot be made interactively during the analysis. On the basis of the results predicted in the first analysis and the selected criterion for removing elements, the analysis is repeated from the very first step, but one or more groups of elements are set to be removed at certain instants. This procedure is repeated several times until there is no zone that satisfies the criterion of element removal. In the beginning of each such analysis, the soil is allowed to consolidate, and the seismic acceleration is then applied at the boundaries of the analysis domain.

The criterion for removal (or deactivation) of elements is selected on the basis of the predicted maximum shear strain $\left(\gamma_{\max }\right)$, and the slope failure is arbitrarily assumed for $\gamma_{\max }>$ $100 \%$. It is important to note that without removal of elements, the extension of failure would be very limited; however, after the removal of failed element groups, continuing failure can be predicted. This also contributes to the decision about the instants at which element removal is performed. In all analyses performed in this study, there exists a certain instant after which no significant increase in shear strains is predicted; that is, the slope stabilizes to some extent. However, after removal, because of the loss of support and the already developed EPWP, failure extends to a greater distance. The above steps are repeated until no further failure occurs (i.e., the criterion for element removal is no longer met). 
Table 2. Cases analysed in this study and predicted lengths of retrogression.

\begin{tabular}{lllll}
\hline Case & Soil materials & General slope of the seafloor & Mesh size & $\begin{array}{l}\text { Predicted length of } \\
\text { retrogression }(\mathrm{m})\end{array}$ \\
\hline 1 & Uniform loose sand & Flat $(\beta=0)$ & Standard & 53 \\
& & & Fine & 55 \\
2 & Sand overlain by silt layer & Flat $(\beta=0)$ & Standard & 213 \\
3 & Uniform loose sand & Gently sloping $\left(\beta=2^{\circ}\right)$ & Standard & 160 and $300^{a}$ \\
4 & Sand overlain by silt layer & Gently sloping $\left(\beta=2^{\circ}\right)$ & Standard & To the boundary \\
\hline
\end{tabular}

${ }^{a}$ These distances depend on the location of the left lateral boundary. These values correspond to the 240 and $400 \mathrm{~m}$ distance between the left lateral boundary and the crest of the slope.

\section{Analysis results}

Four situations were analysed to explain the mechanism of retrogressive failure and to illustrate the effects of a top silt layer and of a very gentle slope angle on the extension of a retrogressive failure (Table 2). The silt layer had considerably smaller permeability than the sand and acted as a barrier layer for EPWP dissipation. The effects of mesh size on the computational results were assessed for one of these cases.

\section{Case 1: Uniform sand, flat seafloor $\left(\boldsymbol{\beta}=0^{\circ}\right)$}

Three stages of retrogression were predicted in this analysis. Three groups of elements were removed at three different instants, which were $t=15 \mathrm{~s}$ (roughly at the end of the earthquake), $t=115 \mathrm{~s}$, and $t=165 \mathrm{~s}$. The instants were selected on the basis of the removal criterion described previously. Figure 4 shows contours of predicted maximum shear strain $\left(\gamma_{\max }\right)$ and EPWP ratio with respect to initial vertical effective stress $\left(r_{\mathrm{u}}\right)$ at selected instants. Because in this case all stages of retrogressive failure were located near the slope, only a small part of the mesh is shown.

At the beginning of the analysis, both the strains and the EPWP are zero in all elements. Gradually, EPWP increases, with maximum values in the free field near the soil surface. Owing to initial static shear stress, the numerical model predicts significantly lower EPWP immediately near the slope than in the free field, that is, left of the slope crest and right of the slope toe. At $t=5 \mathrm{~s}, \gamma_{\max }<25 \%$; however, after $t=$ $6 \mathrm{~s}$ (Fig. 4a), regions of $\gamma_{\max }>25 \%$ start to develop from the midpoint of the slope. The general shape of the contours of $\gamma_{\max }$ is indicative of the location of failure surfaces encountered in classical slope stability analysis, especially those passing through the toe of the slope. In this study, shear strains gradually increase with time near the slope (Fig. 4b). At approximately $t=15 \mathrm{~s}$, the first two columns of elements in the vicinity of the slope have undergone $\gamma_{\max }>$ $100 \%$; that is, these elements satisfy the removal criterion. It should be mentioned that if the analysis were continued with no element removal, the predicted shear strains would remain constant after the end of earthquake, and the predicted extension of slope failure would be about $10 \mathrm{~m}$ from the slope crest.

After the first group of elements is removed, at $t=15 \mathrm{~s}$ (Fig. 4c), except for a very small area there is no region where $\gamma_{\max }>25 \%$. Subsequently, regions of high $\gamma_{\max }$ start to develop gradually, but with a smaller depth and greater lateral extension (Fig. 4d) than those predicted in the first stage. Meanwhile, as the seismic motion has already ended,
EPWPs are now dissipating, as shown by the contours of $r_{\mathrm{u}}$. Note that the marked decrease in $r_{\mathrm{u}}$ in the vicinity of slope immediately after element removal, shown in Fig. $4 c$, is only an artefact of presenting the contours of the EPWP ratio with respect to the initial values of vertical effective stress. As explained later on in this section, as a result of drop in overburden pressure after removal, the real EPWP ratio may increase in this area. At $t=115 \mathrm{~s}$, the second group of elements is removed (Fig. $4 e$ ). After $t=115 \mathrm{~s}$, regions of high $\gamma_{\max }$ develop with smaller depth and lateral extension (Fig. 4f) than predicted previously. This is mainly because most of the EPWPs generated during strong ground motion have already dissipated. At $t=165 \mathrm{~s}$, the third group of elements is removed (Fig. $4 g$ ). By the end of the analysis period $(t=300 \mathrm{~s}), r_{\mathrm{u}}<25 \%$ over the entire analysis domain, and there are no regions where $\gamma_{\max }>100 \%$ (Fig. 4h). Total retrogression distance is approximately $55 \mathrm{~m}$, which has occurred in three stages. The extension of failure after the first two stages is about 10 and $40 \mathrm{~m}$ from the slope crest.

Some of the results predicted for elements E (near slope) and B (free field), as shown in Fig. 2, are presented in Figs. 5 and 6, respectively. Element E belongs to the first group of elements removed at $t=15 \mathrm{~s}$. Element B is located outside the area affected by retrogressive failure.

Figures $5 a$ and $6 a$ present predicted stress paths in terms of horizontal shear stress $\left(\tau_{x y}\right)$ versus vertical effective stress $\left(\sigma_{\mathrm{v}}^{\prime}\right)$. Horizontal shear stress $\left(\tau_{x y}\right)$ versus horizontal shear strain $\left(\gamma_{x y}\right)$ plots are presented in Figs. $5 b$ and $6 b$ for the small strains and in Figs. $5 c$ and $6 c$ for the entire analysis, namely, until the removal of element $\mathrm{E}$ at $t=15 \mathrm{~s}$ (Fig. $5 \mathrm{c}$ ) and until $t=300 \mathrm{~s}$ for element B (Fig. 6c). Finally, Figs. $5 d$ and $6 d$ present the evolution of the EPWP ratio from the beginning to the removal of element $\mathrm{E}$ or to the end of the analysis.

The stress path for element E (Fig. 5a) starts at a point with some initial static shear stress and ends at a point with reduced (but non-zero) effective vertical stress, with only one significant reversal of shear stress. The final state corresponds to the maximum value of $r_{\mathrm{u}} \approx 0.5$ (Fig. $5 d$ ). However, as shown in Figs. $5 b$ and $5 c$, this element starts failing, practically under static shear stress, after $t \approx 5 \mathrm{~s}$. The behaviour of element $\mathrm{E}$ is characteristic of the predicted behaviour of the entire zone near the slope face: softening (reduction of shear strength) due to some EPWP buildup; accumulation of large shear strains; and eventually, failure under static shear stress. Unlike the case for element E, there are significant shear stress reversals in the stress path of element B, and it reaches the state of zero effective stress during shaking (Fig. 6a). Because of the relatively fast dissipation of EPWP 
Fig. 4. Contours of predicted maximum shear strain $\left(\gamma_{\max }\right)$ and excess pore pressure ratio $\left(r_{\mathrm{u}}\right)$ at selected instants in case 1 . Removal times are $t=15,115$, and $165 \mathrm{~s}$.
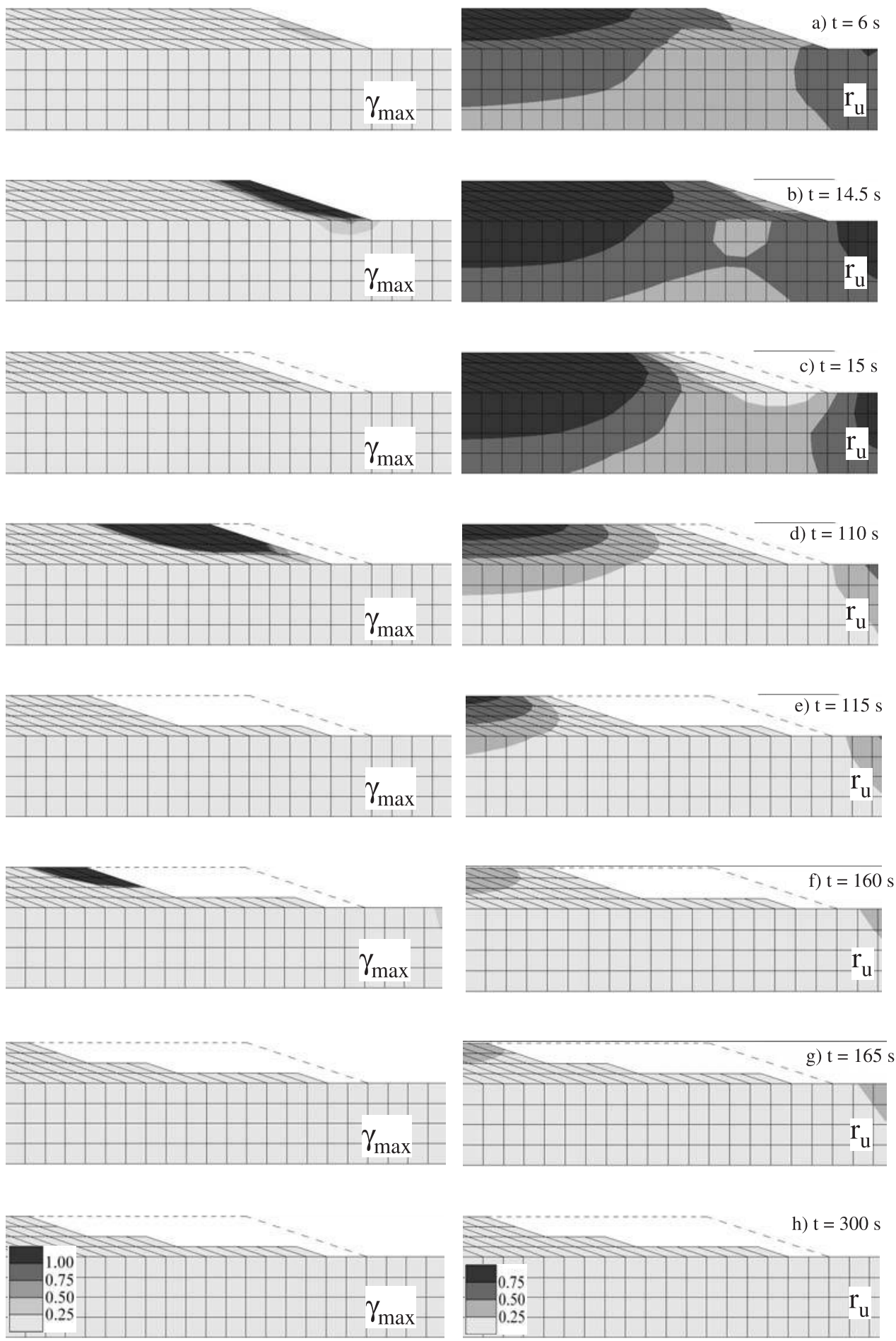

(Fig. 6d), this element regains its strength gradually with the increase in vertical stress (Fig. 6a), before the retrogression front reaches its location. The moments of the second and third element removals ( $t=115$ and $165 \mathrm{~s}$ ) can be observed as slight perturbations in the predicted stress path and EPWP time history of element B (Figs. $6 a$ and $6 d$ ). Large shear strains do not develop, because of the absence of static shear stress (Figs. $6 b$ and $6 c$ ). There is a slight accumulation of

shear strain in element $\mathrm{B}$, which at maximum reaches a value of about $2 \%$ shear strain (Fig. $6 c$ ) and ultimately decreases to a value of about $1.6 \%$ by the end of the analysis.

Figure 7 shows a comparison between the horizontal shear strength of element F (see Fig. 2) when first removal is done and that when no removal is done. Element $\mathrm{F}$ has been selected for this discussion because it is located on the failure surface in the second stage of retrogression. The removal of 
Fig. 5. Case 1, element E (near slope): (a) horizontal shear stress versus effective vertical stress; $(b)$ horizontal shear stress versus horizontal shear strain, low-strain part; $(c)$ horizontal shear stress versus horizontal shear strain, large-strain part; $(d)$ excess pore pressure ratio.

a)

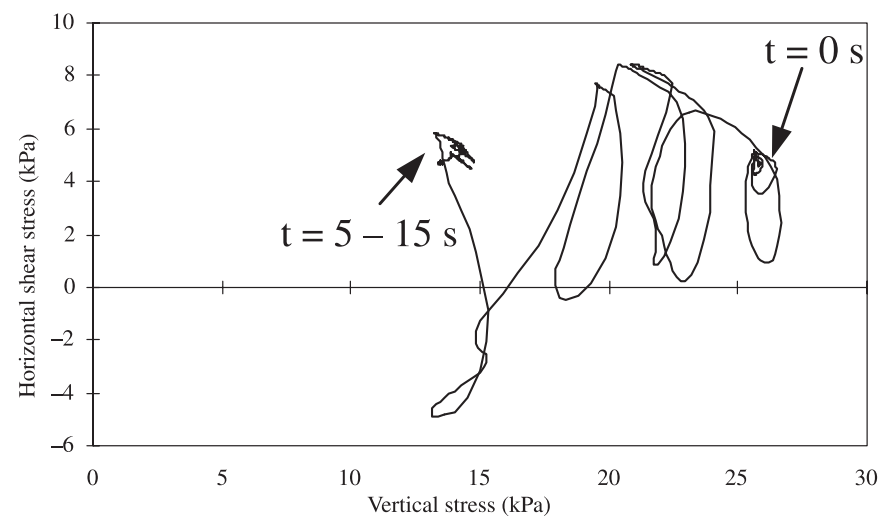

c)

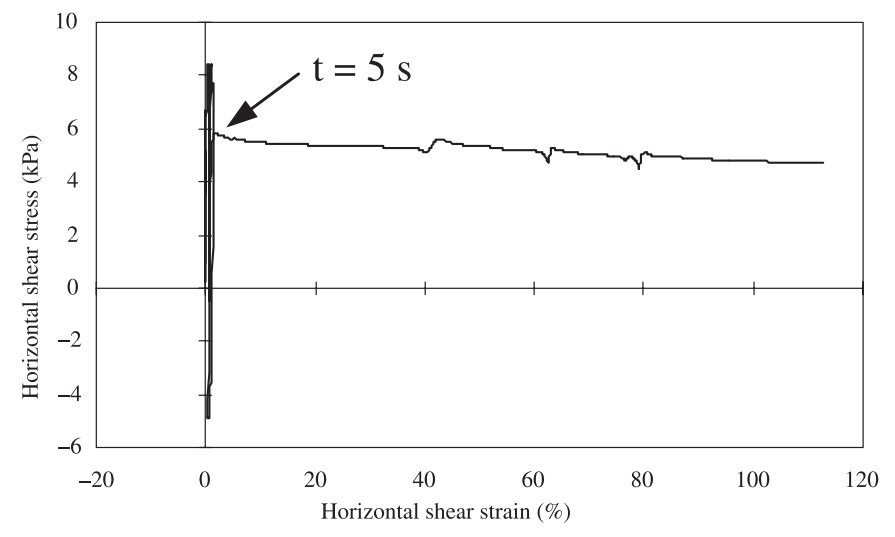

the first group of elements at $t=15 \mathrm{~s}$ results in stress redistribution in the form of a removal of overburden pressure, a decrease in vertical effective stress, and thus a decrease in shear strength, which leads to the failure of the second group of elements, where element $\mathrm{F}$ is located. The element has already experienced some softening due to the increase in EPWP (see Fig. 4). This failure mechanism resembles, to some extent, the mechanism of retrogression initiated by failures in the Fraser River delta, as explained by Chillarige et al. (1997) and mentioned earlier.

Next, the results predicted by the numerical model in terms of EPWP ratio are compared with the predictions made using the simplified procedure of liquefaction analysis (Youd et al. 2001), which is now standard practice for evaluating the liquefaction resistance of soils. In the following, the factor of safety against liquefaction is calculated for locations B (free field) and E (near slope), as shown in Fig. 2. The simplified procedure was primarily developed for soils under level to gently sloping ground and in shallow depths ( $<15 \mathrm{~m}$ ); however, for location $\mathrm{E}$ (near slope), the effect of static shear stresses can be incorporated by the correction factor $K_{\alpha}$, discussed later in more detail. The factor of safety against liquefaction can be calculated as follows (Youd et al. 2001):

$$
F_{\mathrm{s}}=\left(\frac{\mathrm{CRR}_{7.5}}{\mathrm{CSR}}\right) \operatorname{MSF} K_{\sigma} K_{\alpha}
$$

b)

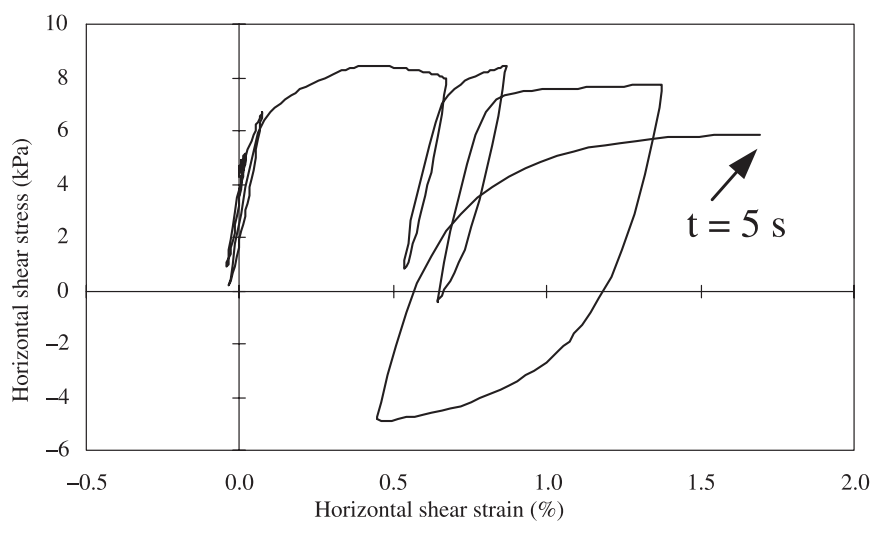

d)

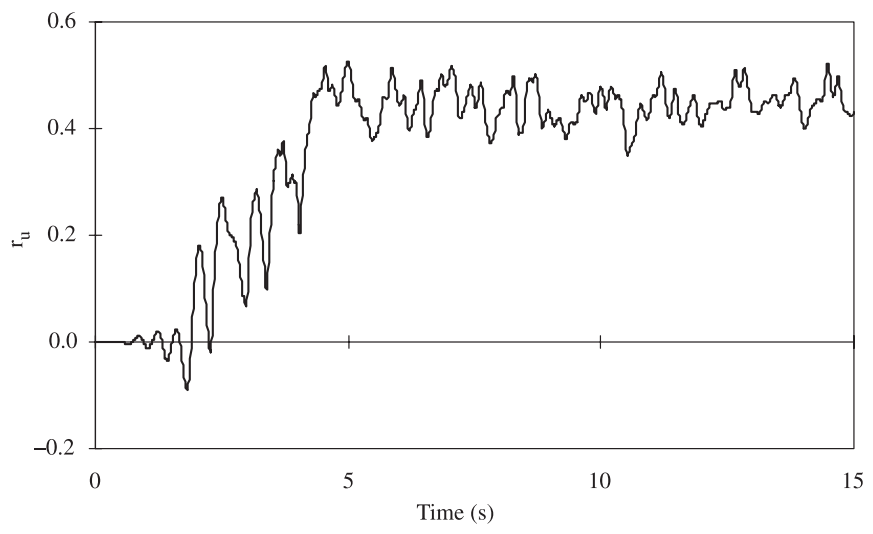

where $\mathrm{CRR}_{7.5}$ is the cyclic resistance ratio for magnitude 7.5 earthquakes; CSR is the cyclic stress ratio induced by the earthquake; MSF is the magnitude scaling factor; and $K_{\sigma}$ and $K_{\alpha}$ account for the effects of overburden pressure and static shear stress, respectively. The value for $\mathrm{CRR}_{7.5}$ may in general be obtained from some correlations based on in situ tests, such as a standard penetration test, a cone penetration test, or a shear wave velocity test. For the initial effective overburden stress at locations B and E, given a standard penetration resistance of $N_{60}=10$ for the sand used in this study (Terzaghi et al. 1996), the normalized blow count, $\left(N_{1}\right)_{60}$, results in 16 and 20, respectively, which correspond to a $\mathrm{CRR}_{7.5}$ of 0.18 and 0.23 (Youd et al. 2001).

CSR is calculated as follows:

$$
\mathrm{CSR}=0.65 \frac{a_{\max }}{g} \frac{\sigma_{\mathrm{v} 0}}{\sigma_{\mathrm{v} 0}^{\prime}} r_{\mathrm{d}}
$$

where $a_{\max }$ is the peak horizontal acceleration at the ground surface; $g$ is acceleration due to gravity; $\sigma_{\mathrm{v} 0}$ and $\sigma_{\mathrm{v} 0}^{\prime}$ are the total and effective vertical overburden stresses at the depth in question; and $r_{\mathrm{d}}$ is the stress reduction factor, which provides an approximate correction for flexibility of the soil profile (Youd et al. 2001). For the present submarine slope, since the shear strength of the water above the soil can be neglected, the ratio of total to effective stress is equal to the ratio of saturated to buoyant unit weights, which for this soil is 
Fig. 6. Case 1, element B (free field): (a) horizontal shear stress versus effective vertical stress; $(b)$ horizontal shear stress versus horizontal shear strain, low-strain part; $(c)$ horizontal shear stress versus horizontal shear strain, large-strain part; $(d)$ excess pore pressure ratio.

a)

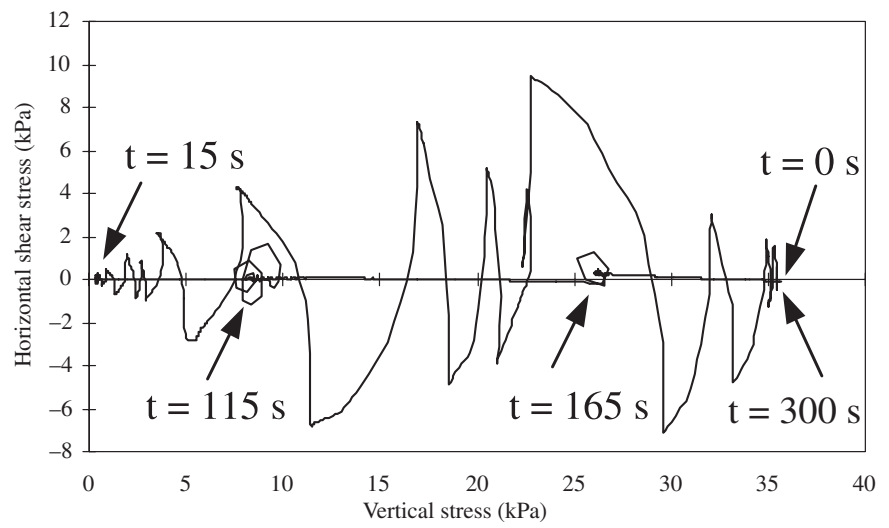

c)

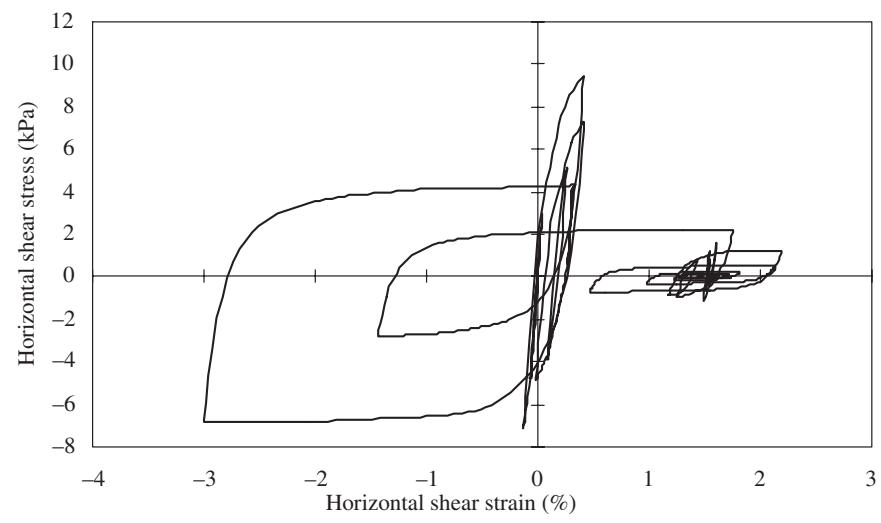

b)

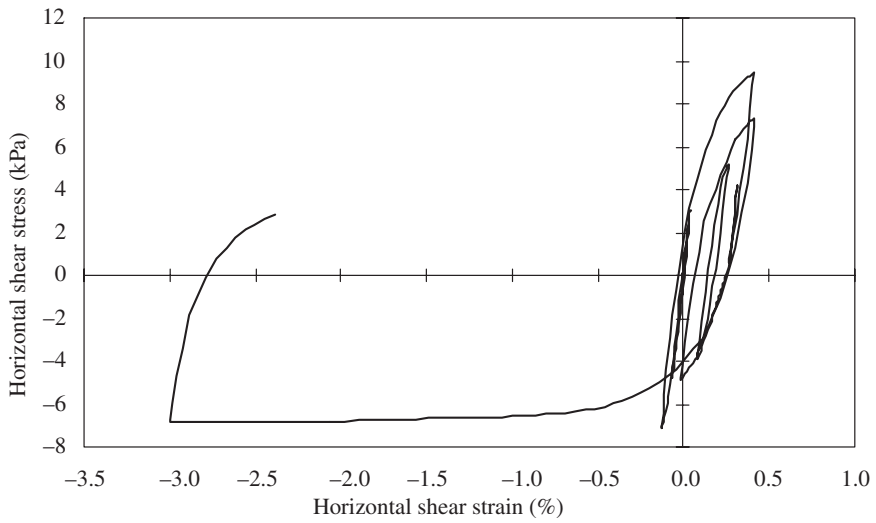

d)

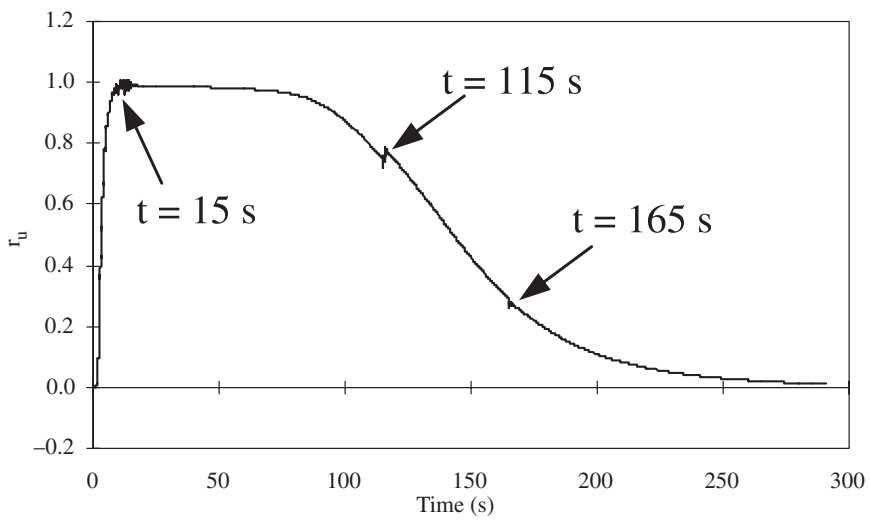

Fig. 7. Horizontal shear strength of element $\mathrm{F}$ with and without removal of the first group at $t=15 \mathrm{~s}$.

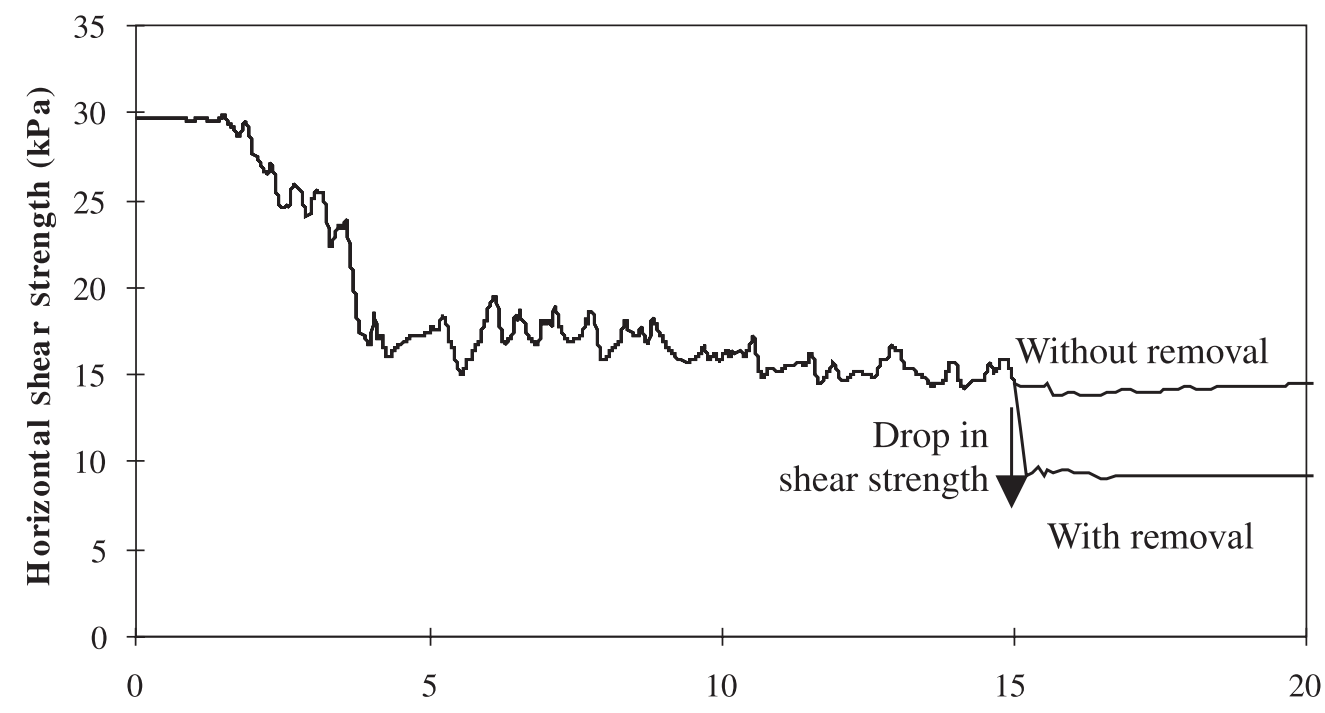

Time (s)

about 2. Using $a_{\max }=0.3 g$ and $r_{\mathrm{d}}=0.96$ results in CSR $=$ 0.37 .

If the concept of equivalent number of uniform stress cycles at $0.65 \tau_{\max }$, proposed by Seed et al. (1975), is used, the acceleration-time history has about 12.4 equivalent number of cycles and corresponds to an earthquake of magnitude 7.0. Therefore, given the values recommended by Youd et al. (2001), MSF is approximately equal to 1.2. For both lo- 
Fig. 8. Contours of $\gamma_{\max }$ and $r_{\mathrm{u}}$ at selected instants in case 2. Note that the first and second removal times are $t=15$ and $165 \mathrm{~s}$ in this analysis.
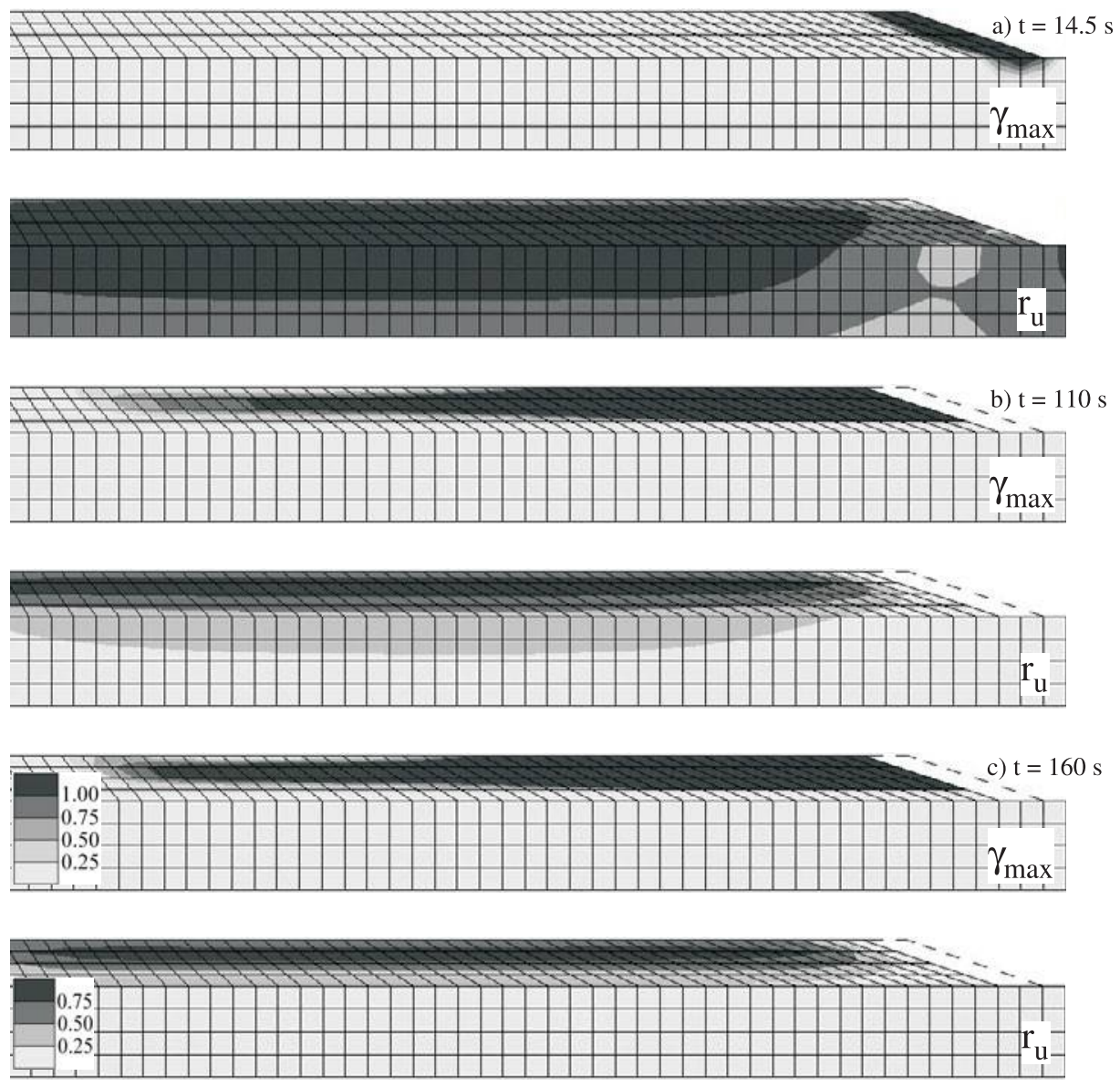

Fig. 9. Predicted profile at the end of retrogression for case 2, showing the five stages of element removal. Removal times are $t=15$, $165,240,340$, and $390 \mathrm{~s}$.

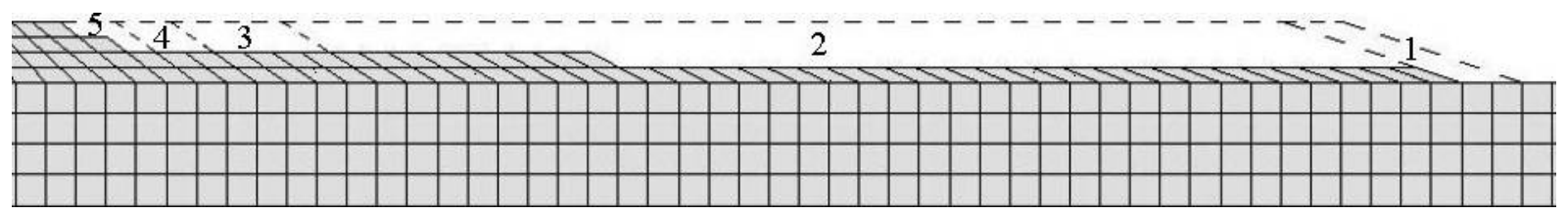

cations $\mathrm{B}$ (free field) and $\mathrm{E}$ (near slope), $K_{\sigma}=1$, because the initial vertical effective stresses are $<100 \mathrm{kPa}$. At location $\mathrm{B}$, $K_{\alpha}=1$ and $K_{\alpha}=1.6$ at location E, after Vaid et al. (2001) and corresponding to a static shear stress of $\alpha=\tau_{\mathrm{st}} / \sigma_{\mathrm{v} 0}^{\prime}=$ 0.18 , where $\tau_{\mathrm{st}}$ is the static shear stress; and $\sigma_{\mathrm{v} 0}^{\prime}$ is the initial effective vertical stress.

With the above values, the factors of safety against liquefaction, $F_{\mathrm{s}}$, predicted according to eq. [1] for locations B and E, are 0.58 and 1.18 , respectively. Those factors, obtained on the basis of the current state of practice, confirm the analysis results that predict liquefaction for location B (zero effective stress, with $\left.r_{\mathrm{u}}=1\right)$ and no liquefaction for location $\mathrm{E}\left(r_{\mathrm{u}} \approx\right.$ $0.5)$.

\section{Case 2: Sand overlain by silt layer, flat seafloor $\left(\boldsymbol{\beta}=\mathbf{0}^{\circ}\right)$}

The only difference between case 2 and case 1 is that in the top $2.5 \mathrm{~m}$ the sand is replaced with a silt layer with a permeability 20000 times lower (see Fig. 2). Predicted contours of the maximum shear strain $\left(\gamma_{\max }\right)$ and the EPWP ratio $\left(r_{\mathrm{u}}\right)$ at selected instants are presented in Fig. 8 . The removal of the first group of elements is performed at $t=15 \mathrm{~s}$, on the basis of the distribution of $\gamma_{\max }$. This is the same instant as for case 1 , because until $t=15 \mathrm{~s}$, contours of $\gamma_{\max }>$ $100 \%$ and $r_{\mathrm{u}}>75 \%$ are observed to be more or less the same in both cases 1 and 2 . Five stages of retrogression are predicted in this case. Removed groups of elements are shown in Fig. 9. The removal times are 15, 165, 240, 340, and $390 \mathrm{~s}$, respectively. The extensions of failure in each stage, measured from the slope crest, are approximately 10 , $180,195,205$, and $213 \mathrm{~m}$, respectively, with a total extent of retrogression about four times larger than that predicted for case 1. An explanation for the large difference in the results for cases 1 and 2 is presented below.

Figure 10 shows the variation of the EPWP ratio with 
Fig. 10. Variation of excess pore pressure ratio $\left(r_{\mathrm{u}}\right)$ with time and depth in cases 1 and 2 . Locations of elements A-D are shown in Fig. 2. In (b), elements $\mathrm{A}-\mathrm{C}$ belong to the second group removed at $t=165 \mathrm{~s}$ in case 2 .
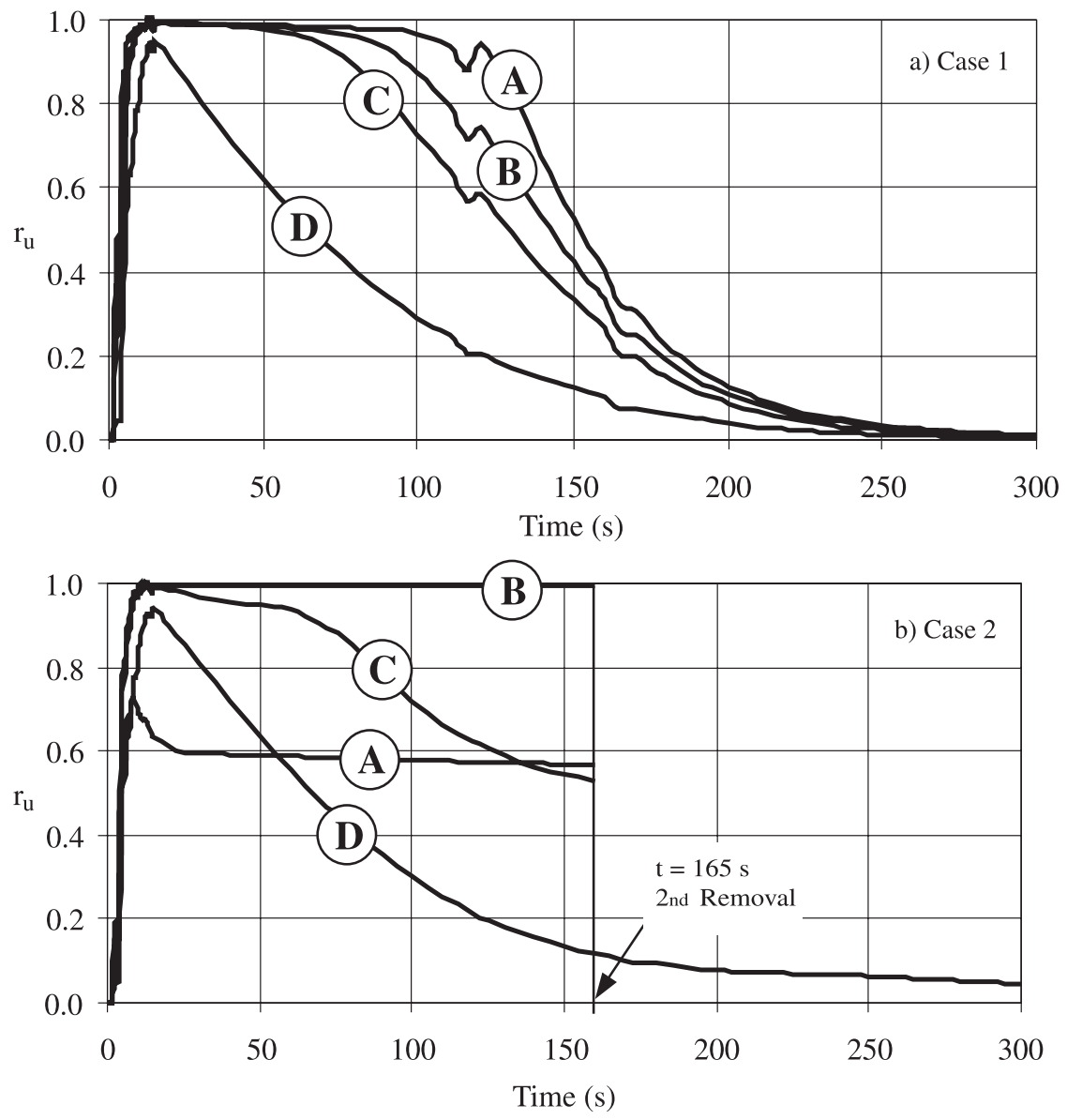

Fig. 11. Case 2, element B (second removed group): (a) horizontal shear stress versus effective vertical stress; $(b)$ horizontal shear stress versus horizontal shear strain.

a)

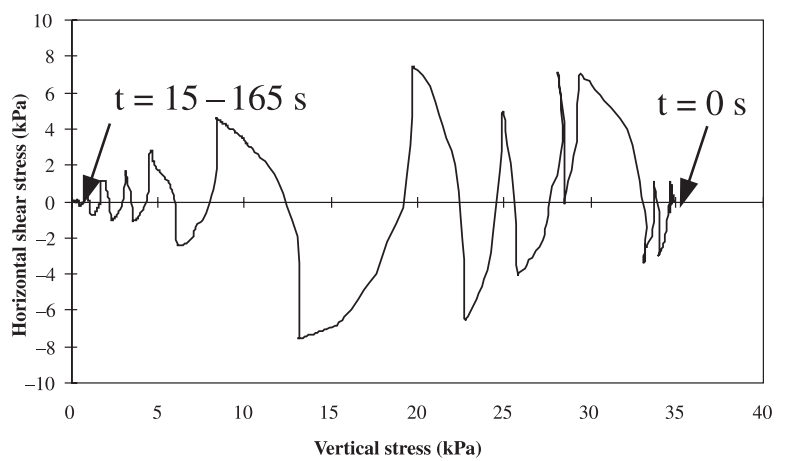

time for cases 1 and 2, at elements A to D (locations shown in Fig. 2). In case 1 (Fig. 10a), the dissipation rate is much faster than in case 2 (Fig. 10b) because vertical seepage is very much slowed down by the presence of the silt layer. Therefore, although at $t=14.5 \mathrm{~s}$ (i.e., very close to the end of shaking), contours of $\gamma_{\max }>100 \%$ and $r_{\mathrm{u}}>75 \%$ are more or less the same in both cases 1 and 2 (see Figs. $8 a$ and $4 b$ ); at $t=110 \mathrm{~s}$ (before the second removal), the contour of b)

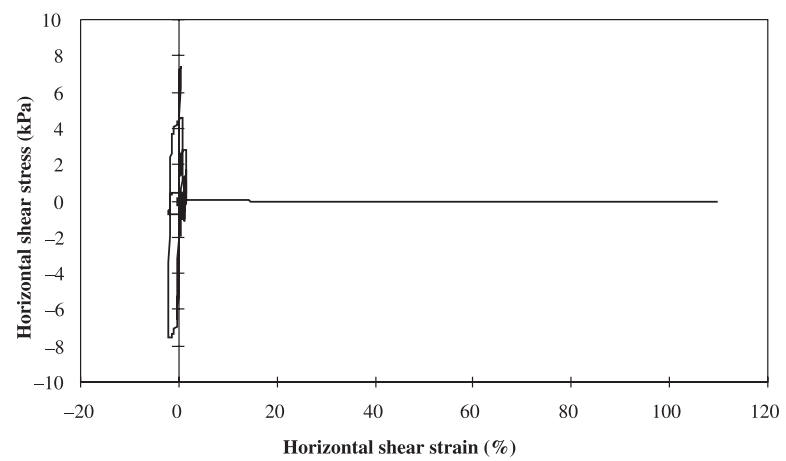

$\gamma_{\max }>100 \%$ predicted for case 2 extends over a much greater distance than in case 1 (Figs. $8 b$ and $4 d$ ).

Figure 11 shows the stress path and the shear stress-strain plots for element B (see Fig. 2) in case 2; this element belongs to the second group of elements removed at $t=165 \mathrm{~s}$. For element B in cases 1 and 2, the key difference in behaviours is caused by the very low rate of EPWP dissipation in case 2 (see Fig. 10), as a result of the presence of the less 
Fig. 12. Contours of $\gamma_{\max }$ at selected instants in case 3 . Removal time is $t=15 \mathrm{~s}$.

a) $\mathrm{t}=14.5 \mathrm{~s}$

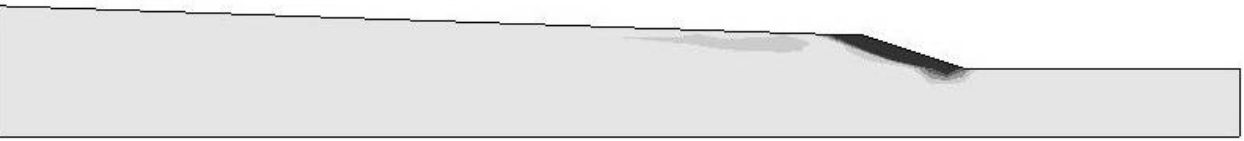

b) $\mathrm{t}=110 \mathrm{~s}$

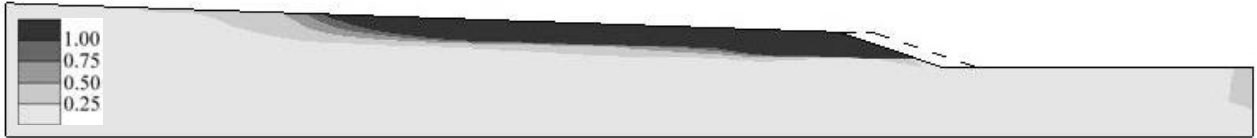

Fig. 13. Variation of $r_{\mathrm{u}}$ with depth at the end of shaking in cases 3 (continuous line) and 4 (dotted line) and the limit value of $r_{\mathrm{u}}$ required for infinite slope failure (dash-dot line).

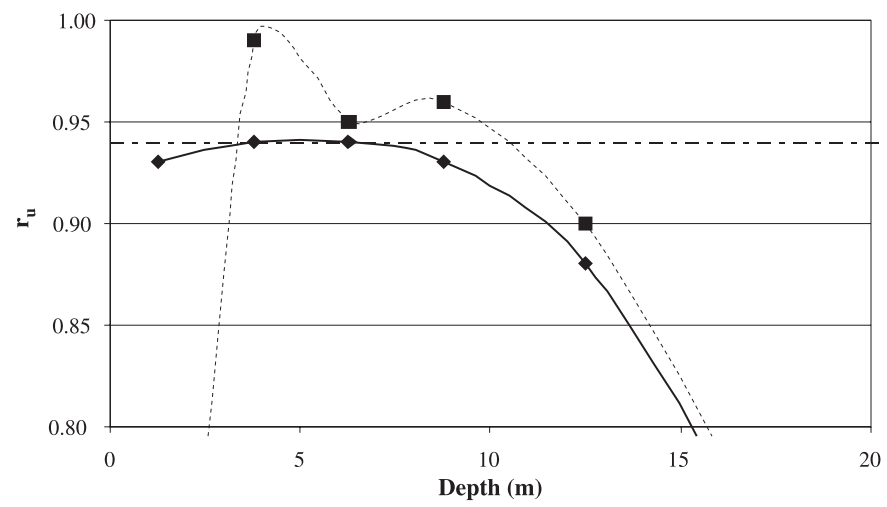

permeable top silt layer. Although the stress paths of both elements during shaking are somewhat similar (compare Figs. $11 a$ and $6 a$ ), these paths are completely different after shaking. In case 2 , since $r_{\mathrm{u}}$ remains equal to 1 until the removal of this element at $t=165 \mathrm{~s}$ (see Fig. 10b), the stress path remains close to the origin, that is, zero vertical effective stress (Fig. 11a). Element B undergoes very large shear strains under very small shear stress (Fig. 11b), as a result of liquefaction and loss of support.

\section{Case 3: Uniform sand, sloping seafloor $\left(\beta=2^{\circ}\right)$}

In this case, the seafloor located to the left of the slope crest (see Fig. 2) is gently sloped at $\beta=2^{\circ}$. Only contours of $\gamma_{\max }$ are shown in Fig. 12, mainly because the distribution of $r_{\mathrm{u}}$ is roughly similar to that predicted in case 1 , and the significant difference lies in the distribution of $\gamma_{\max }$. It is predicted that a slight increase in the slope of the seafloor would result in a substantial increase in the retrogression distance to $160 \mathrm{~m}$ from approximately $40 \mathrm{~m}$ (after only two stages). It was observed, however, that for this case the retrogression distance is affected by the presence of the left lateral boundary of the analysis domain. For example, in an analysis with the lateral boundary located at $400 \mathrm{~m}$ from the slope crest, it was observed that the predicted retrogression distance was approximately $300 \mathrm{~m}$. In this case (both meshes), the second stage of failure occurred in the upper 5$7 \mathrm{~m}$ of the seafloor, similar to what was predicted in case 2 . The second stage of failure is indicative of an infinite slope failure mechanism that occurs in a liquefied layer after loss of support induced by the first stage of retrogression. Thus, the failure extends to a great distance, depending on the lo- cation of the rigid boundary. In nature, however, such retrogressive failure can be limited by the presence of stiffer or denser soil layers or changes in seafloor morphology. Note that if no element removal is done, the numerical model will not predict slope failure beyond the first stage.

The occurrence of infinite slope failure can be explained on the basis of the classical method of slope stability as follows. The static factor of safety against sliding for an infinite slope (without seepage) is given by $F_{\mathrm{s}}=\tan \phi / \tan \beta$, where $\phi$ is the soil friction angle and $\beta$ is the slope angle. For $\phi=$ $31^{\circ}$ and $\beta=2^{\circ}, F_{\mathrm{s}}=17.2$. (Note that the static factor of safety obtained by the ordinary method of slices for the $1: 3$ $V / H$ slope is about 2.6.) After the end of shaking, however, as a result of the buildup of EPWP, which yields to reduction in effective normal stress, the factor of safety drops significantly. The new factor of safety depends on the value of EPWP ratio, $r_{\mathrm{u}}$, according to the following equation (e.g., Zangeneh and Popescu 2003):

$$
F_{\mathrm{s}}=\frac{\tan \phi}{\tan \beta}\left(1-r_{\mathrm{u}}\right)
$$

For the geometry and soil characteristics analysed here, any value of $r_{\mathrm{u}}$ greater than 0.94 results in a value of $F_{\mathrm{s}}<1$ and therefore failure. The continuous line in Fig. 13 shows the distribution of the EPWP ratio with depth at the end of shaking along a vertical line where the elements A to D in Fig. 2 are located. The depth above which EPWP $>0.94$ is between 4 and $6 \mathrm{~m}$. It approximately corresponds to the depth to which the contour of $\gamma_{\max }>100 \%$ extends (as shown in Fig. 12b).

\section{Case 4: Sand overlain by silt layer, sloping seafloor $\left(\boldsymbol{\beta}=2^{\circ}\right)$}

The most important observation from this case is that the silt layer again affects the retrogression distance significantly (Fig. 14). The failure at $t=110 \mathrm{~s}$ extends to greater depth and length $(>200 \mathrm{~m})$ than predicted for either case 2 or case 3. This is caused by larger values of EPWP that because of the presence of the silt layer cannot dissipate upward as they do in case 3. The dotted line in Fig. 13 shows the distribution of the EPWP ratio with depth at the end of shaking. Compared with the continuous line (case 3$), r_{u}$ is higher in the sand and is $>0.94$ to a depth of about $10 \mathrm{~m}$. This results in a failure surface that is flatter than the seafloor slope of $2^{\circ}$ and that extends to a greater depth. Again, the predicted retrogression distance is limited by the boundary conditions, as discussed for case 3 . 
Fig. 14. Contours of $\gamma_{\max }$ at selected instants in case 4. Removal time is $t=15 \mathrm{~s}$.

$$
\text { a) } \mathrm{t}=14.5 \mathrm{~s}
$$

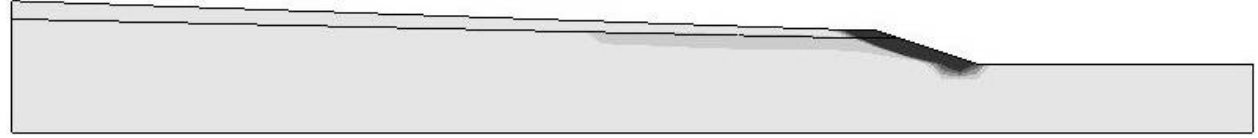

b) $\mathrm{t}=110 \mathrm{~s}$

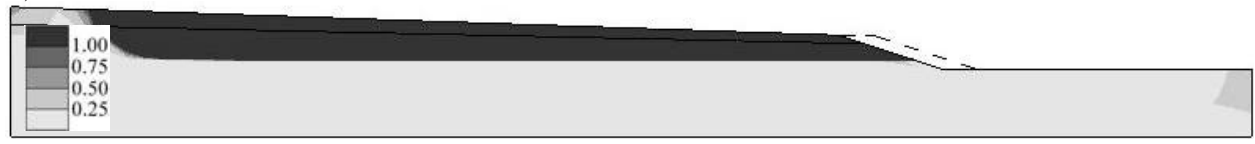

Fig. 15. Contours of $\gamma_{\max }$ and $r_{\mathrm{u}}$ at selected instants in case 5. Removal times are $t=15,90,115$, and $165 \mathrm{~s}$.
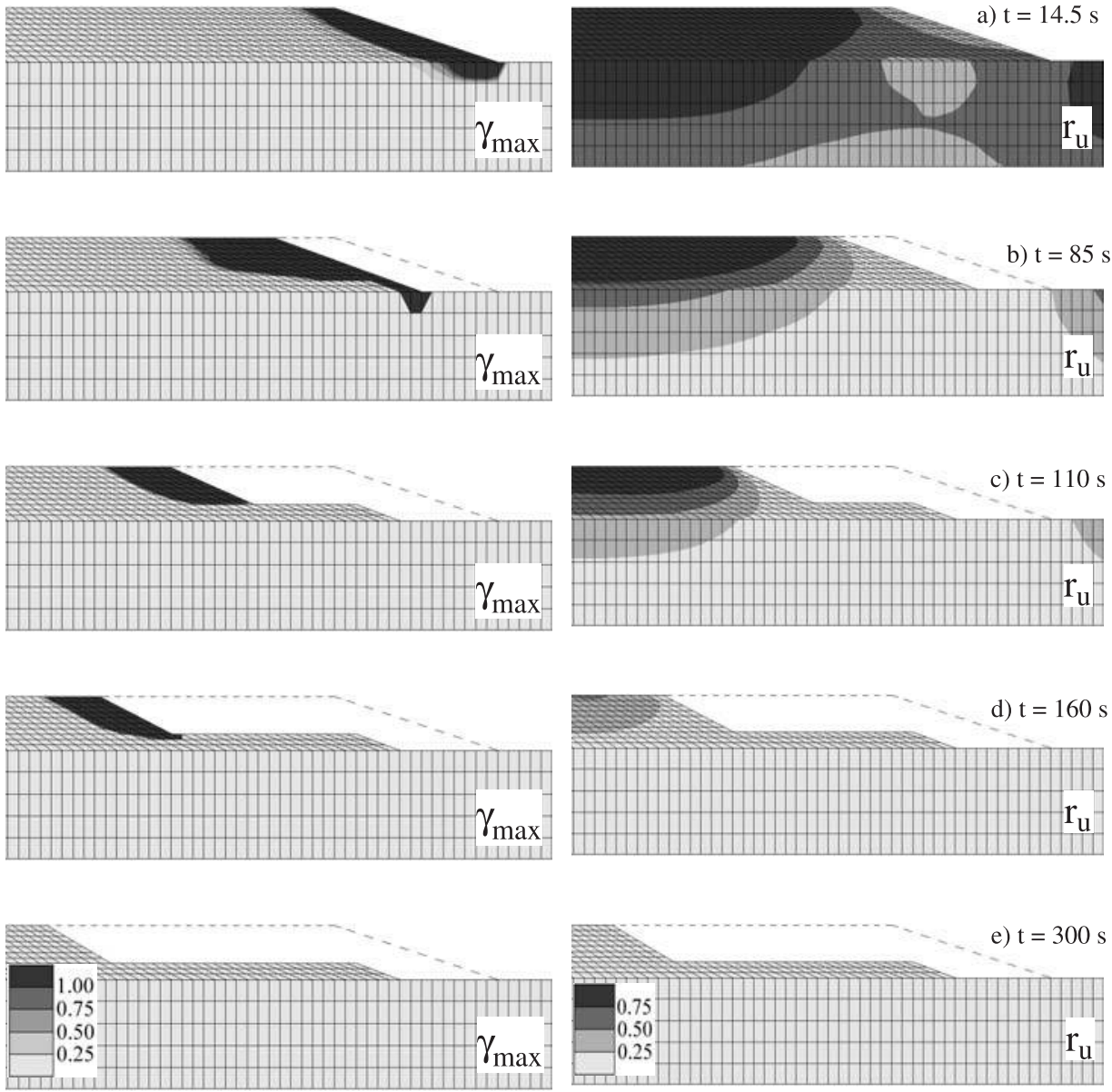

\section{Effect of mesh refinement}

To determine the effects of finite element mesh size on the numerical results, case 1 (uniform sand and flat seafloor) was reanalysed with a finer mesh (see Fig. $2 b$ ). Some of the results of the analysis are shown in Fig. 15, at instants before each removal and at the end of analysis. The removal times are $15,90,115$, and $165 \mathrm{~s}$, with extensions of failure approximately equal to $10,22,42$, amd $53 \mathrm{~m}$, respectively. A comparison with numerical results obtained for the standard mesh shows that the final extension of failure is approximately equal in the two cases $(55 \mathrm{~m}$ for the standard mesh vs. $53 \mathrm{~m}$ for the fine mesh). There are, however, small differences in the intermediate results. The numbers of retrogression stages are different, that is, three versus four, and

the shapes of the predicted final (stable) profiles (after end of retrogression) are slightly different, with deeper failure predicted when a finer mesh is used. When the standard mesh is used, the depth of failed region in each stage is less than in its previous stage, whereas when the fine mesh is used, this reduction takes place only after the first stage. Overall, from the results of this limited study, it is deemed that mesh refinement does not significantly affect the results of the analysis.

\section{Limitations of the study}

An important limitation of the analysis reported here was caused by the lateral boundary conditions, especially those 
to the left of the slope. Although the boundaries were located far enough away that they did not affect the distributions of $\gamma_{\max }$ and $r_{\mathrm{u}}$ in the vicinity of the steeper slope, it is obvious that in cases 3 and 4, the extension of the failure was limited by the boundaries of the mesh. Yet, it should be noted that it is quite possible that the stratigraphic sequence at the site was such that presence of more resistant soil layers could limit the retrogression distance, which somehow resembles the situation considered in this case. Another limitation came from the assumption that the failed mass completely separates from the deposit and flows away. This does not necessarily always happen. In some failures, the failed mass may remain for a longer period near the slope toe and act as a surcharge. Finally, there was no quantitative validation of the proposed method of analysis. As no complete set of data from a real case history (including morphology and geomechanical properties, geometry of slope failure, seismic excitation) was available, the only validation of this study was qualitative, coming from evidence of several retrogressive submarine slope failures triggered by seismic events. Such a quantitative comparison with field observations is in particular needed to assess the validity of the proposed removal criterion. Both the shear strain threshold $\left(\gamma_{\max }>100 \%\right)$ and the timing for removal were set somewhat arbitrarily in this study. It is also worth noting that in this procedure, the strain localization phenomenon was not directly taken into account. However, as explained for case 1, regions of high shear strain started to develop from the midpoint of the slope, and the general shape of the contours of $\gamma_{\max }$ is indicative of the location of failure surfaces encountered in classical slope stability analysis.

\section{Summary and conclusions}

It has been shown how the retrogressive failure of seafloor, initiated by earthquake, can be simulated by using the finite element method. The procedure has been illustrated by four numerical examples that explain a number of different mechanisms of initiation and retrogression of failure. The analyses emphasize the effects of a silt layer and a gently sloping seafloor on the retrogression of slope failure in a sand deposit.

If the presented procedure is not used, that is, no removal of failed elements is done, the predicted extension of failure will be at least five times smaller, and hence the results of the analysis will be underconservative. Such a difference would be only an order of magnitude, and it could vary as a function of soil properties, morphology, seismic acceleration, etc.

It has been found that a silt layer and a gentle seafloor slope significantly affect the retrogression distance by increasing it by at least four to five times, as compared with a flat, uniformly sandy seafloor. The element removal was the key feature that allowed more realistic simulations in all cases. The mechanism of initial failure, triggered by the earthquake shaking, was failure under static shear stress while maximum EPWP ratio near the slope face was well below 1; that is, liquefaction did not occur. After element removal, reduction in overburden pressure resulted in a reduction of shear strength, and the initial failure retrogressed to regions that had already experienced softening because of
EPWP buildup. In case of uniform sand, because of the relatively fast rate of dissipation, which results in regaining strength for the soil, the extension of retrogression was considerably smaller than for the case where the sand was overlain by a less permeable silt layer. For a gently sloping seafloor, the initial failure caused an infinite slope failure mechanism in the deposit, which had lost most of its shear strength as a result of the buildup of pore pressure. The extension of the retrogression could be limited in the field by particular geomorphological conditions. When infinite slope failure was predicted (cases 3 and 4), the resulting failure surface was parallel to the seabed (i.e., inclined at $2^{\circ}$ ) for the uniform soil and flatter for the layered soil. A limited study also showed that mesh refinement could slightly affect the number of retrogression stages in the analysis but would not affect the predicted extension of failure.

\section{Acknowledgements}

This study is part of COSTA-Canada, a Canadian contribution to the study of continental slope stability. The financial support provided by the Natural Sciences and Engineering Research Council of Canada under Grant No. RG203795-02 is also acknowledged.

\section{References}

AEA Technology. 1999. CFX-4.3: flow solver user guide. AEA Technology, Oxford, London, U.K.

Andersen, A., and Bjerrum, L. 1967. Slides in subaqueous slopes in loose sand and silt. In Marine geotechnique. Edited by A.F. Richards. Illinois Press, Urbana, Ill. pp. 221-239.

Anderson, M.G., and Richards, K.S. 1987. Slope stability, geotechnical engineering and geomorphology. John Wiley \& Sons, New York.

Boe, R., Hovland, M., Instanes, A., Rise, L., and Vasshus, S. 2000. Submarine slide scars and mass movements in Karmsundet and Skudenesfjorden, southwestern Norway: morphology and evolution. Marine Geology, 167: 147-165.

Bugge, T., Befring, S., Belderson, R.H., Eidvin, T., Jansen, E., Kenyon, N.H., et al. 1987. A giant three-stage submarine slide off Norway. Geo-Marine Letters, 7: 191-198.

Carson, M.A., and Lajoie, G. 1981. Some constraints on the severity of landslide penetration in sensitive deposits. Géographie physique et Quaternaire, 35: 301-316.

Chillarige, A.V., Morgenstern, N.R., Robertson, P.K., and Christian, H.A. 1997. Seabed instability due to flow liquefaction in the Fraser River delta. Canadian Geotechnical Journal, 34: 520 533.

COSTA-Canada. 2000. [online]. Available from http://www.costacanada.ggl.ulaval.ca/ [accessed on 11 November 2002].

De Blasio, F.V., Issler, D., Elverhøi, A.C., Harbitz, B., Bryn, P., and Lien, R. 2003. Dynamics and material properties of the giant Storegga slide as suggested by numerical simulations. In Proceedings of the 1st International Symposium on Submarine Mass Movements and their Consequences, Nice, France, April 2003. Edited by J. Locat and J. Mienert. Kluwer Academic Publishers, Dordrect. pp. 223-230.

Edwards, B.D., Lee, H.J., and Field, M.E. 1995. Mudflow generated by retrogressive slope failure, Santa Barbara Basin, California continental borderland. Journal of Sedimentary Research, A65(1): 57-68. 
Gardner, J.V., Prior, D.B., and Field, M.E. 1999. Humboldt slidea large shear-dominated retrogressive slope failure. Marine Geology, 154: 323-338.

Hampton, M.A., Lee, H.J., and Locat, J. 1996. Submarine landslides. Reviews of Geophysics, 34(1): 33-59.

Hansen, A. 1984. Landslide hazard analysis. In Slope instability. Edited by D. Brundsen and D.B. Prior. John Wiley \& Sons, New York. pp. 523-602.

Haug, M.D., Sauer, E.K., and Fredlund, D.G. 1976. Retrogressive slope failures near Saskatoon. In Proceedings of the 29th Canadian Geotechnical Conference, Vancouver, B.C., October 1976. Canadian Geotechnical Society. pp. II-66-II-83.

ICBO. 1994. Uniform Building Code. Vol. 2. International Conference of Building Officials, Whittier, Calif.

Issler, D., De Blasio, F.V., Elverhøi, A., Ilstad, T., Bryn, P., and Lien, R. 2003. Issues in the assessment of gravity mass flow hazard in the Storegga area off the western Norwegian coast. In Proceedings of the 1st International Symposium on Submarine Mass Movements and their Consequences, Nice, France, April 2003. Edited by J. Locat and J. Mienert. Kluwer Academic Publishers, Dordrect. pp. 231-238.

Keanne, C.M., and Prévost, J.H. 1989. An analysis of earthquake data observed at the Wildlife Liquefaction Array Site, Imperial County, California. In Proceedings of the 2nd US-Japan Workshop on Liquefaction, Large Ground Deformations and Effects on Lifelines, Buffalo, N.Y., September 1989. Edited by T.D. O'Rourke and M. Hamada. National Center for Earthquake Engineering Research, State University of New York, Buffalo, N.Y. pp. $39-53$.

Kvalstad, T.J., Gauer, P., Kaynia, A.M., Nadim, F., and Bryn, P. 2002. Slope stability at Ormen Lange. In Diversity and Sustainability, Proceedings of the International Conference on Offshore Site Investigation and Geotechnics. Society for Underwater Technology, London, UK.

Lemke, R.W. 1967. Effects of the earthquake of March 27, 1964, at Seward, Alaska. US Geological Survey, Professional Paper 542-E.

Leroueil, S., Locat, J., Vaunat, J., Picarelli, L., Lee, H., and Faure, R. 1996. Geotechnical characterization of slope movements. In Proceedings of the 7th International Symposium on Landslides, Trondheim, Norway. A.A. Balkema, Rotterdam, The Netherlands. pp. 53-74.

Locat, J., and Lee, H.J. 2002. Submarine landslides: advances and challenges. Canadian Geotechnical Journal, 39(1): 193-212.

Mitchell, R.J., and Markell, A.R. 1974. Flowsliding in sensitive soils. Canadian Geotechnical Journal, 11: 11-31.

Mosher, D.C., Monahan, P.A., and Barrie, J.V. 2001. Submarine failures in the Strait of Georgia, British Columbia: landslides of the 1946 Vancouver Island Earthquake. In Proceedings of the 54th Canadian Geotechnical Conference, Calgary, Alta., 1619 September 2001. Edited by M. Mahmoud, R. Van Everdingen, and J. Carss. Bitech Publishers Ltd., Richmond, B.C. Vol. 2, pp. 744-751.

Mulder, T., and Cochonat, P. 1996. Classification of offshore mass movements. Journal of Sedimentary Research, A66: 43-57.

Piper, D.J.W., Cochonat, P., Ollier, G., Le Dreezen, E., Morrison, M.L., and Baltzer, A. 1992. Évolution progressive d'un glissement rotationnel en un courant de turbidité : cas du séisme de 1929 des Grands Bancs (Terre-Neuve). Comptes rendus de l'Académie des sciences, série II, 314: 1057-1064.

Piper, D.J.W., Cochonat, P., and Morrison, M.L. 1999. The sequence of events around the epicentre of the 1929 Grand Banks earthquake: initiation of debris flows and turbidity current inferred from sidescan sonar. Sedimentology, 46: 79-97.
Popescu, R. 1995. Stochastic variability of soil properties: data analysis, digital simulation, effects on system behavior. Ph.D. thesis, Princeton University, Princeton, N.J.

Popescu, R., and Prévost, J.H. 1993. Centrifuge validation of a numerical model for dynamic soil liquefaction. Soil Dynamics and Earthquake Engineering, 12(2): 73-90.

Popescu, R., and Prévost, J.H. 1995. Comparison between VELACS numerical 'class A' predictions and centrifuge experimental soil test results. Soil Dynamics and Earthquake Engineering, 14(2): 79-92.

Popescu, R., Prévost, J.H., Ohbo, N., and Hayashi, K. 1992. Numerical simulations of soil liquefaction, In Proceedings of the 4th US-Japan Workshop on Liquefaction, Large Ground Deformations, and Effects on Lifelines, Honolulu, Hawaii. Edited by M. Hamada and T.D. O'Rourke. National Center for Earthquake Engineering Research, State University of New York, Buffalo, N.Y. pp. 269-282.

Popescu, R., Prévost, J.H., and Deodatis, G. 1998. Seismic analysis of a wharf seawall. In Proceedings of the Structural Engineers World Congress (SEWC), San Francisco, Calif., 19-23 July 1998. [available on CD-ROM].

Prévost, J.H. 1985. A simple plasticity theory for frictional cohesionless soils. Soil Dynamics and Earthquake Engineering, 4(1): 9-17.

Prévost, J.H. 2002. DYNAFLOW: a nonlinear transient finite element analysis program. Version 2002. Release 01.A. Department of Civil Engineering and Operations Research, Princeton University, Princeton, N.J.

Prior, D.B., and Coleman, J.M. 1978. Disintegrative retrogressive landslides on very-low-angle subaqueous slopes, Mississippi delta. Marine Geotechnology, 3: 37-60.

Prior, D.B., and Coleman, J.M. 1984. Submarine slope instability. In Slope instability. Edited by D. Brundsen and D.B. Prior. Wiley, New York. pp. 419-445.

Sasitharan, S., Robertson, P.K., Sego, D.C., and Morgenstern, N.R. 1993. Collapse behavior of sand. Canadian Geotechnical Journal, 30: 569-577.

Seed, H.B. 1968. Landslides during earthquakes due to soil liquefaction. Journal of the Soil Mechanics and Foundations Division, ASCE, 94: 1053-1122.

Seed, H.B., Idriss, I.M., Makdisi, F., and Banerjee, N. 1975. Representation of irregular stress-time histories by equivalent stress series in liquefaction analyses. Earthquake Engineering Research Center, University of California, Berkeley, Calif. Report No. EERC 75-29.

Sladen, J.A., D'Hollander, R.D., Krahn, J., and Mitchell, D.E. 1985. Back analysis of the Nerlerk berm liquefaction slides. Canadian Geotechnical Journal, 22: 579-588.

Terzaghi, K. 1956. Varieties of submarine slope failures. In Proceedings of the 8th Texas Conference in Soil Mechanics and Foundation Engineering. pp. 1-41.

Terzaghi, K., Peck, R.B, and Mesri, G. 1996. Soil mechanics in engineering practice. 3rd ed. John Wiley \& Sons, New York.

Urgeles, R., Locat, J., Lee, H., Martin, F., and Konrad, J.M. 2001. The Saguenay Fjord: integrating marine geotechnical and geophysical data for spatial slope stability hazard analysis. In Proceedings of the 54th Canadian Geotechnical Conference, Calgary, Alta. 16-19 September 2001. Edited by M. Mahmoud, R. Van Everdingen, and J. Carss. Bitech Publishers Ltd., Richmond, B.C. Vol. 2, pp. 768-775.

Vaid, Y.P., Stedman, J.D., and Sivathayalan, S. 2001. Confining stress and static shear effects in cyclic liquefaction. Canadian Geotechnical Journal, 38(3): 580-591. 
Youd, T.L., Idriss, I.M., Andrus, R.D., Arango, I., Castro, G., Christian, J.T., et al. 2001. Liquefaction resistance of soils: summary report from the 1996 NCEER and 1998 NCEER/NSF Workshops on Evaluation of Liquefaction Resistance of Soils. Journal of Geotechnical and Geoenvironmental Engineering, ASCE, 127(10): 817-833.
Zangeneh, N., and Popescu, R. 2003. Displacement analysis of submarine slopes using enhanced Newmark method. In Proceedings of the 1st International Symposium on Submarine Mass Movements and their Consequences. Nice, France, April 2003. Edited by J. Locat and J. Mienert. Kluwer Academic Publishers, Dordrect. pp. 193-202. 